\title{
Is It Worth the Effort? The Impact of Incorporating Synchronous Lectures into an Online Course
}

\author{
Joann S. Olson \\ University of Houston- Victoria \\ Fawn E. McCracken \\ Crown College
}

\begin{abstract}
This study explores student achievement, sense of social community, and sense of learning community (Rovai, 2002) in two sections of an online course taught concurrently by the same instructor. One section was delivered in a fully asynchronous format; the other incorporated weekly synchronous lectures using an Adobe Connect environment. Students were randomly assigned to one of the two sections but allowed to change sections (before the semester began) if unwilling or unable to participate in weekly Adobe Connect meetings. Data included grades on course assignments, final course grades, end-of-course evaluations, and responses to the Classroom Community Inventory (Rovai, Wighting \& Lucking, 2004). No significant differences were found on measures of academic achievement, student satisfaction, social community, or learning community between the two sections.
\end{abstract}

\section{Introduction}

Engagement and participation are often highlighted as key components of excellence and effectiveness within online courses (e.g., Palloff \& Pratt, 2011). Students, faculty, and administrators alike have explored the addition of synchronous activities into existing course work as a means of increasing immediacy (Schutt, Allen \& Laumakis, 2009) or "teaching presence” (Garrison \& Anderson, 2003) in online education. As bandwidth becomes increasingly affordable and access to the Internet increasingly assumed, adding course components such as real-time lectures or group discussions using web conferencing may, indeed, increase student engagement and learning. This is a move that makes sense, intuitively: when students and teachers can interact and respond in real time, perceptions of student-to-student and student-to-teacher contact (Falloon, 2011; Pattillo, 2007) and a sense of community (Hratinski, 2008) may increase. 
Is It Worth the Effort? The Impact of Incorporating Synchronous Lectures into an Online Course

However, incorporating synchronous technology requires significant investments in terms of technological infrastructure, faculty development, and student technical competence. In addition, students who may have been drawn to the "no set schedule" nature of a fully asynchronous learning environment may not wish to-or may not be able to-navigate the time constraints of scheduled synchronous sessions. This may be particularly challenging for students who rely on public-access technology (e.g., computer labs at schools or libraries) when they do not have sufficient bandwidth or technological resources at home. What happens to these students if the computer lab happens to be unavailable when the class session is scheduled to begin? It is important to consider whether the real and perceived benefits outweigh the real and perceived costs of these synchronous activities.

This article describes a case study in which one section of an online course incorporated weekly synchronous lectures and another section of the same course (taught by the same instructor) was delivered in a fully asynchronous format. The research questions driving the study were: (1) Is there a significant difference in student achievement and satisfaction when using synchronous video conferencing sessions in a primarily asynchronous distance education course? and (2) Is there a significant difference in students' sense of learning community and social community when adding synchronous video conferencing sessions to a primarily asynchronous distance education course? In other words: Is it worth the effort?

\section{Literature Review}

Given the inherent promise of real-time interaction for increasing student engagement and achievement, many have looked to synchronous activities within online learning, often assuming that it will serve as a way to increase "presence" and immediacy in online courses. Researchers have explored various applications for this technology and results have varied. This literature review explores the relationship between synchronous activities and aspects of "presence" in an online course, the impact of incorporating synchronous activities upon other aspects of the online course, and the suitability of the Classroom Community Inventory (Rovai, 2002) to measure aspects of community within online courses.

\section{"Presence in Online Courses"}

Palloff and Pratt (2011) have highlighted "establishing presence" as the "first order of business" (p. 7) for online instructors. Their concept of presence highlighted the social aspects of interacting online: visibility, interpersonal connection, and self-expression that work together to foster points of connection between learners who are physically separated from one another. Other ideas of presence have highlighted cognitive and academic interactions in online courses, such as Garrison \& Anderson's (2003) description of teaching presence. Baker (2010) found that students in asynchronous courses rated their instructors lower, in terms of immediacy, than those in synchronous courses. Baker also found that synchronous students recorded higher levels of presence than asynchronous students, an outcome echoed in research reported by Rockinson-Szapkiw, Baker, Neukrug, and Haynes (2010). Students who participated in synchronous web-conferencing reported that instructors felt less distant during the course and attributed this to the impact of synchronous discussion groups (Patillo, 2007). Hrastinski, Keller, and Carlsson (2010) suggested that synchronous activities can be effectively used to support strong relationships and participation in group projects within a larger class. At the same time, Hrastinski et al. also noted that "weak ties" are developed among "class-wide relations" (p. 656) when synchronous communication is used for lectures or whole-group discussions. These weak ties may result in "decreased cognitive effort” (p. 656) among the group, when compared to asynchronous learning activities.

Increasing presence is likely about more than simply adding synchronous activities into a course, however. Schutt, Allen, and Laumakis (2009) used a combination of delivery methods (video, audio, and text) and instructor behaviors to pinpoint the effect of both setting and instructor behavior upon students' perceptions of immediacy and social presence. They reported that video-enabled computer conferencing does seem to help an instructor communicate the behaviors that are important for conveying immediacy in an online classroom, but that the technology alone does not increase the sense of immediacy. In other 
Is It Worth the Effort? The Impact of Incorporating Synchronous Lectures into an Online Course

words, as Schutt et al. stated: "If an instructor fails to employ immediacy behaviors, students are more likely to perceive him/her as nonimmediate, regardless of whether the communication environment is (a) video- and audio-enabled or (b) only audio-enabled" (p. 144). They further highlighted the role of instructor training in promoting immediacy and presence, regardless of the media or technologies employed. Stafford and Lindsey (2007), on the other hand, suggested that the social orientation of the student and the perception of learning using technology strongly influence the student's perception of teleconferenced courses. Furthermore, the work of Hall and Herrington (2010) called attention to the impact of a learner's cultural context on his or her comfort level when participating synchronously (or asynchronously). Based on their research, they suggested that students from more typically collectivist cultures may find synchronous conversations to be a more effective medium for discussion, as it promotes consensus and group processing, where as those from more individualistic cultures may be more comfortable with the independent, declarative nature of asynchronous discussions.

\section{Synchronous Instruction in Online Education}

As evidenced in the literature, incorporating synchronous activities into online courses can have an impact on course outcomes, although this impact may not always be what course designers or instructors had hoped for. Johnson (2008) rotated students through asynchronous and synchronous discussions of course-related case studies and examined both academic achievement and students' selfreported perception of which mode they felt to be more effective for their own learning, finding no evidence that students preferred one mode over the other. At the same time, courses that included synchronous sessions have, in some cases, also shown increased activity in asynchronous course components (e.g., discussion posts; Spencer \& Hiltz, 2003). Participants in Falloon's (2011) study indicated that while the synchronous session may have allowed for the dissemination of more information and may have facilitated trust-building within the course, they also felt they did not have enough time when working in a synchronous environment to reflect deeply on the content and or comments made by others before they were required to respond.

It seems, therefore, that students may utilize asynchronous and synchronous activities in different, complementary ways in the service of their learning. Teng, Chen, Kinshuk, and Leo (2012) found that students used text [chat] messages primarily to bring greater clarity rather than to engage in synthesis or evaluation of course materials. Oztok, Zingaro, Brett, and Hewitt (2013) noted that students who participated most actively in synchronous components of the class were also likely to be the most active in asynchronous activities in the course. Hrastinski (2008) found that students used asynchronous elearning for "cognitive participation" whereas synchronous e-learning more often increases "personal participation" (p. 54) that may increase commitment and motivation. He concluded that researchers in online education should move beyond trying to determine whether synchronous or asynchronous instruction was the "best" medium and turn attention to the strengths and contributions of each to students' learning.

The inclusion of synchronous technology does introduce an element of unpredictability to the learning environment (Melkun, 2012). A power or Internet outage that produces mild frustration for students in an asynchronous environment can be a significant disruption when occurring during a synchronous teaching session. In addition, as discussed earlier, students who rely on public-access technology (e.g., libraries or school computer labs) may find they are unable to access course resources at the specific time required by the instructor. Researchers have also found that structural elements of the course, such as course organization or lack of clarity regarding the purpose for incorporating synchronous elements, influence a student's engagement with the class (Falloon, 2011).

Rovai and others have conducted research related to classroom community in asynchronous learning settings (Rovai, 2001a; Rovai, 2001b); television-based distance education (Rovai \& Lucking, 2003), and blended learning environments (Rovai \& Jordan, 2004). Taken as a whole, these studies suggest that while the setting and format of the course may shape students' experience, the actions of the instructor play a significant role in fostering community within the classroom. In several studies, participants highlighted the impact of the instructor's familiarity with the synchronous technology in 
Is It Worth the Effort? The Impact of Incorporating Synchronous Lectures into an Online Course

facilitating effective and meaningful learning environments (e.g., Bower, 2011; Exter, Korkmaz, Harlin, \& Bichelmeyer, 2009; Falloon, 2011). For students in Exter et al.'s (2009) study, the instructor's comfort with technology was a key component in their evaluation of the course.

Moving beyond the question of whether asynchronous or synchronous learning is "better," as suggested by Hrastinski (2008), this study seeks to understand the development of social and learning community within an accelerated (five-week) undergraduate course where the synchronous session highlighted material related to one specific assignment each week. By exploring the differences in learning outcomes and perceptions of social and learning community as experienced by two sections of the same course - one delivered fully asynchronously and the other incorporating synchronous lecturesthis study seeks to address several gaps in the literature. The intervention focused the synchronous sessions toward the promoting and evaluating the student's cognitive participation (Hrastinski, 2008) in an online course rather than what may be the default contribution of synchronous technology, namely, the promotion of personal participation (Hrastinski, 2008). In addition to comparing student achievement across two sections of a course taught using various synchronous and asynchronous modalities, this study also seeks an understanding of any variations in student perceptions and experiences of social and learning community.

\section{Methods}

This study sought to explore the impact of adding synchronous lectures to an otherwise asynchronous, online, undergraduate course. Researchers sought the cooperation of an experienced online (adjunct) instructor who had indicated an interest in incorporating new strategies and emerging technologies into online courses. Undergraduate courses in the Adult and Graduate Studies division of this small, faith-based college in the Upper Midwest were offered in an accelerated, five-week format; most courses are 3-credit courses. During one particular five-week section, the instructor was assigned to teach two sections of the same undergraduate course. The design team, comprised of the two authors of this article, the instructor for the course, and the Division's curriculum coordinator, selected these two sections to evaluate the impact of incorporating synchronous technology into online courses in the form of weekly lectures delivered using Adobe Connect. The two sections were offered during the same calendar period and used the same syllabus, assessments, asynchronous discussion questions, and grading scale. The design team identified one assignment each week that would be highlighted and discussed during weekly synchronous lectures, referred to herein as the "targeted assignments."

\section{Participants}

As students registered for this class, they were assigned randomly to either the fully asynchronous (ASYNC) or the asynchronous+synchronous (ASYNC+SYNC) section. Since almost all of the online courses offered by this division are fully asynchronous, the design team recognized that the additional requirement of "set time and place" synchronous activity might prove to be a hardship for students. Therefore, when students were assigned to the ASYNC+SYNC section, they received an e-mail explaining the format of the class, describing the synchronous section, outlining the participation requirements, and asking about their willingness to participate. We moved students out of the ASYNC+SYNC section if they requested ASYNC; we then asked a randomly selected student from the ASYNC section if they would be willing to participate in ASYNC+SYNC section and adjusted registrations as necessary. Even though this strategy may have introduced the possibility of selection bias, it was the best way to honor the time and scheduling expectations of our students. As the class began, 16 students agreed to participate in the ASYNC+SYNC section; 22 were enrolled in ASYNC.

\section{Course Design}

As the design team developed the syllabus, both sections were assigned the same readings, discussion forum questions, and graded assessments. ASYNC and ASYNC+SYNC students were given the same assignments (e.g., weekly asynchronous discussion posts, response paper, etc.) and course 
Is It Worth the Effort? The Impact of Incorporating Synchronous Lectures into an Online Course

materials (e.g., supplemental readings, un-narrated PowerPoint presentations, etc.) throughout the course; assignments and discussion forum responses were graded according to the same criteria.

Students in ASYNC+SYNC were required to participate in one Adobe Connect session each week; the instructor facilitated one session on Thursday evening, led another on Saturday morning, and also made the recordings available to students. Students chose the session that fit their schedule. For each week of the course, the team identified one writing assignment that would be the focus of the synchronous session. During the Adobe Connect session, the instructor delivered content and led realtime discussions related to that assignment, discussed PowerPoint presentations closely related to the assignment, asked for input from students, and interacted with students via the chat feature of Adobe Connect. The instructor also discussed the requirements of that particular assignment and responded to students' questions.

The design team made the decision to mute students' microphones to reduce technical disruptions such as spending significant time helping students get microphones set up, multiple speakers "talking over" each other, and so on. We recognize that this tactic did limit some of the spontaneity of a "live" discussion; however, we were primarily interested in minimizing potential technical difficulties and frustrations for the students as most were unfamiliar with this type of technology. As researchers, we see the potential for incorporating a full range of audio and video technologies into online courses. In this instance, however, our roles as educators and administrators mandated that we limit the synchronous activities to a real-time lecture with text-based chatting, as we did not want technical issues to impede students' educational experiences. Students were encouraged to attend a pre-class preview of Adobe Connect conducted by the curriculum coordinator, and the first author spent several hours with the instructor in face-to-face and remote practice sessions with Adobe Connect prior to the first synchronous session of the class.

\section{Instrumentation and Data Collection}

Given that we allowed students to switch out of the section they had been randomly assigned to as described earlier, the study is best described as a quasi-experimental design to evaluate postintervention measurements of non-equivalent groups. At the close of the course, students in both ASYNC and ASYNC+SYNC sections completed an end-of-course evaluation that included demographic information, an overall course evaluation, and instructor ratings. This end-of-course evaluation included the 10 items of the Classroom Community Inventory (CCI; Rovai, 2002; Rovai, Wighting \& Lucking, 2004), which was designed to measure perceptions of social community and learning community in online classrooms. Social community items include "I trust others in this course" and "I feel that students in this course care about each other." Learning community items include items such as I feel that I am given ample opportunities to learn in this course" and "I feel that my educational needs are not being met in this course." The CCI was validated using a sample of both traditional and online students. The CCI also separates the concepts of "social community" and "learning community," which was an important distinction, given that we were interested in the impact of the synchronous environment on both the academic and relational experiences of students in these classes. We also used open-ended questions to gather overall perceptions of various course elements. In addition, we collected overall course grades as well as grades for specific assignments throughout the class. Data were analyzed using SPSS in relation to the research questions.

\section{Results}

The research questions driving this study explore student achievement and sense of community in response to incorporating synchronous lectures into an online course. Therefore, we compared the two sections on various measures, including course grades, satisfaction with course and instructor, and measures of social and learning community (as measured by the Classroom Community Inventory). Of the 22 students enrolled in ASYNC, 10 (45.5\%) completed end-of-course evaluations (including demographic indicators and the Classroom Community Inventory); 10 of 16 (62.5\%) students enrolled in 
Is It Worth the Effort? The Impact of Incorporating Synchronous Lectures into an Online Course

ASYNC+SYNC completed the end-of-course materials. Student demographics for those completing endof-course materials are found in Table 1.

Table 1 Student Demographics

\begin{tabular}{ccc}
\hline & \multicolumn{1}{c}{ ASYNC } & ASYNC+SYNC \\
Age $20-29$ & 2 & 3 \\
$30-39$ & 4 & 2 \\
$40-49$ & 3 & 3 \\
$50-59$ & 1 & 2 \\
$60-69$ & 0 & 0 \\
Female & 6 & 5 \\
Male & 4 & 5 \\
\hline
\end{tabular}

\section{Course Grades and Assessments}

To evaluate the impact of the synchronous sessions on student achievement, we compared grades in the two sections after final grades were posted. Using the official course gradebook as recorded in the learning management system, we analyzed grade data for all 36 students, as detailed in Table 2. "Discussion Forums" refers to grades for all asynchronous discussion forums assigned throughout the class, generally two per week during the five-week session. "Targeted assignments" represents grades on assessments that were selected by the design team as the focus of each synchronous presentation. Students in ASYNC and ASYNC+SYNC completed the same assignments and were graded according to the same criteria. Overall course grades and assignment-specific grades were slightly higher in the asynchronous section, but none of these differences rose to the $\mathrm{p}<.05$ level.

Table 2 Course Grades in ASYNC and ASYNC+SYNC Sections

\begin{tabular}{|c|c|c|c|c|c|c|c|c|}
\hline & \multicolumn{3}{|c|}{ ASYNC } & \multicolumn{3}{|c|}{ ASYNC+SYNC } & \multirow[b]{2}{*}{$t$-test } & \multirow[b]{2}{*}{$p$} \\
\hline & Mean & & $S D$ & $\mathrm{Mea}$ & & $S D$ & & \\
\hline $\begin{array}{l}\text { Discussion } \\
\text { (250 points possible) }\end{array}$ & 230.9 & (92.4\%) & 29.4 & 212.4 & (85.0\%) & 50.6 & 1.304 & .205 \\
\hline $\begin{array}{l}\text { “Targeted” Assignments } \\
\text { (225 points possible) }\end{array}$ & 209.0 & $(92.8 \%)$ & 18.5 & 198.1 & $(88.0 \%)$ & 46.4 & 0.885 & .388 \\
\hline $\begin{array}{l}\text { Final Course Grade } \\
\text { (all assignments) }\end{array}$ & & $88.8 \%$ & 9.2 & & $84.1 \%$ & 22.1 & 0.804 & .431 \\
\hline
\end{tabular}

Assignment details, such as late submissions or assignment length, were not part of any formal analysis, but the design team noticed that as the class progressed, ASYNC+SYNC students tended to submit assignments after posted deadlines more frequently than students in the ASYNC section. It is possible that students who chose to participate in the Saturday synchronous sessions then found it difficult to complete the assignment by the posted Sunday evening deadline.

\section{End-of-Course Evaluation}

At the end of the class, students completed standard course evaluation forms, detailed in Table 3. These end-of-of course evaluations asked students to complete an online evaluation using a 5-point Likert-type scale (with 5 being "strongly agree") to rate various aspects of the course such as timely grading, instructor feedback, and so on. 
Is It Worth the Effort? The Impact of Incorporating Synchronous Lectures into an Online Course

Table 3 Comparison of Course Evaluation Items between ASYNC and ASYNC+SYNC

\begin{tabular}{|c|c|c|c|c|c|c|}
\hline & \multicolumn{2}{|c|}{$\underline{\text { ASYNC }}$} & \multicolumn{2}{|c|}{$\begin{array}{l}\text { ASYNC+ } \\
\text { SYNC }\end{array}$} & \multirow[t]{2}{*}{$\begin{array}{l}\text { Mann- } \\
\text { Whitney U }\end{array}$} & \multirow[t]{2}{*}{ Exact Sig. } \\
\hline & Mean & $S D$ & Mean & $S D$ & & \\
\hline $\begin{array}{l}\text { I feel that students in this course care about } \\
\text { each other. (SC) }\end{array}$ & 4.3 & 0.7 & 4.2 & 0.6 & 45.5 & .739 \\
\hline $\begin{array}{l}\text { I feel connected to others in this course. } \\
\text { (SC) }\end{array}$ & 3.8 & 1.1 & 3.6 & 0.8 & 42.0 & .579 \\
\hline I trust others in this course. (SC) & 4 & 0.7 & 4.1 & 0.6 & 41.0 & .780 \\
\hline $\begin{array}{l}\text { I feel that I can rely on others in this course. } \\
\text { (SC) }\end{array}$ & 3.7 & 0.9 & 3.8 & 0.9 & 46.5 & .796 \\
\hline $\begin{array}{l}\text { I feel confident that others in this course } \\
\text { will support me. (SC) }\end{array}$ & 3.8 & 0.9 & 4.1 & 0.6 & 41.5 & .529 \\
\hline $\begin{array}{l}\text { I feel that I receive timely feedback in this } \\
\text { course. (LC) }\end{array}$ & 3.8 & 1 & 3.9 & 0.6 & 48.0 & .912 \\
\hline $\begin{array}{l}\text { I feel that this course results in only modest } \\
\text { learning. (LC) }\end{array}$ & 2.4 & 1.1 & 2.8 & 1.2 & 40.0 & .481 \\
\hline $\begin{array}{l}\text { I feel that I am given ample oppor-tunities } \\
\text { to learn in this course. (LC) }\end{array}$ & 4.1 & 0.9 & 4.2 & 0.9 & 45.5 & .739 \\
\hline $\begin{array}{l}\text { I feel that my educational needs are not } \\
\text { being met in this course. (LC) }\end{array}$ & 1.9 & 1 & 2 & 1.4 & 47.5 & .853 \\
\hline $\begin{array}{l}\text { I feel that this course does not promote a } \\
\text { desire to learn. (LC) }\end{array}$ & 1.7 & 0.8 & 1.4 & 1 & 36.5 & .315 \\
\hline $\begin{array}{l}\text { On a scale of } 1 \text { to } 5 \text { ( } 5 \text { being Excellent): } \\
\text { How would you rate this course? }\end{array}$ & 4.1 & 0.7 & 4.2 & 0.7 & 41.0 & .780 \\
\hline $\begin{array}{l}\text { On a scale of } 1 \text { to } 5 \text { ( } 5 \text { being Excellent): } \\
\text { How would you rate the online course } \\
\text { instructor? }\end{array}$ & 4.4 & 0.7 & 4.3 & 0.7 & 42.5 & .842 \\
\hline $\begin{array}{l}\text { The course syllabus was clear and easy to } \\
\text { understand. }\end{array}$ & 4.2 & 0.6 & 4.4 & 0.5 & 42.0 & .579 \\
\hline $\begin{array}{l}\text { This course contained adequate and helpful } \\
\text { audiovisual materials. }\end{array}$ & 3.5 & 0.8 & 3.8 & 0.9 & 39.5 & .436 \\
\hline $\begin{array}{l}\text { I was challenged to look at my life, my } \\
\text { goals, and my worldview through this } \\
\text { course. }\end{array}$ & 4.3 & 0.7 & 4.3 & 0.7 & 50.0 & 1.000 \\
\hline $\begin{array}{l}\text { This course required an appropriate amount } \\
\text { of work. }\end{array}$ & 4 & 0.8 & 3.6 & 1.1 & 40.0 & .481 \\
\hline $\begin{array}{l}\text { The course syllabus accurately reflected } \\
\text { course content. }\end{array}$ & 4.1 & 0.7 & 4.3 & 0.7 & 42.5 & .579 \\
\hline $\begin{array}{l}\text { The instructor provided adequate feedback } \\
\text { on assignments. }\end{array}$ & 4.1 & 1 & 4.3 & 0.5 & 48.0 & .912 \\
\hline $\begin{array}{l}\text { The instructor was actively engaged in } \\
\text { course discussions. }\end{array}$ & 3.9 & 1.2 & 4.1 & 1 & 46.5 & .796 \\
\hline $\begin{array}{l}\text { The instructor integrated a biblical } \\
\text { perspective throughout the course. }\end{array}$ & 4.5 & 1 & 4.6 & 0.5 & 47.0 & .853 \\
\hline
\end{tabular}

Note. "SC" indicates item from the social community scale of the Classroom Community Inventory; "LC" indicates an item from the learning community scale of the Classroom Community Inventory (Rovai, 2002).

Students are not required to complete these evaluations and response rates are typically low. As indicated above, $45.5 \%$ of ASYNC students and $62.5 \%$ of ASYNC+SYNC students completed the evaluations. Therefore, $\mathrm{n}=10$ for each section. Students also provided an "overall" rating for both 
Is It Worth the Effort? The Impact of Incorporating Synchronous Lectures into an Online Course

instructor and course. A Mann-Whitney U test examining the differences on these measures of student satisfaction between the two sections showed no statistically significant differences between ASYNC and ASYNC+SYNC, as outlined in Table 3. This is due, at least in part, to small sample sizes resulting from small class sizes and low response rate to the end-of-course evaluation materials.

\section{ASYNC+SYNC student response to using Adobe Connect}

Understanding students' level of comfort with technology, in general, and with online learning, in particular, is important for evaluating the extent to which the synchronous environment may have impeded or otherwise influenced their experience in the class. Therefore, we added several questions to the end-of-course evaluation materials for students in ASYNC+SYNC specifically related to their comfort level with technology. In terms of comfort with an online learning environment, two students indicated that this course had been their first online experience; seven of the 10 ASYNC+SYNC respondents indicated they had taken at least five classes in an online environment.

We presented students with a 5-point scale (5 being "excellent") and asked them to rate their comfort level with new technology. All ASYNC+SYNC students selected 4 or 5 on this scale. We also asked these students if they felt that the chat/synchronous sessions using Adobe Connect had been an added benefit in the course. Eight of 10 students selected "agree" or "strongly agree," two selected "neutral," and there were no "disagree" or "strongly disagree" responses. We recognize that students less comfortable with technology may have opted out of the ASYNC+SYNC section and elected to stay with a more familiar asynchronous-only course design; the students who initially opted to stay in the ASYNC+SYNC section may have been more comfortable with technology and therefore more prone to find benefit in the inclusion of the synchronous lectures than students from ASYNC may have been.

\section{Responses to open-ended prompts}

The standard end-of-course evaluation (for both ASYNC and ASYNC+SYNC sections) included a space for students to respond to open-ended prompts regarding the class. Students in both sections commented on the heavy workload required by the course, with one ASYNC+SYNC student concluding "but this is a third-year [300-level] class so that is understandable." One ASYNC student noted the professor's "very good interaction during the discussion boards and afterwards in the submitted lessons," and another indicated that the course materials were "helpful and informative." ASYNC+SYNC students expressed mixed opinions regarding the synchronous course elements. One student described it as "good for personal instruction." At the same time, another student described the Adobe Connect sections as "off track and not focused on class materials." Another commented that "some of the chats could have been more beneficial," although that student did not elaborate on what would have added to the effectiveness of the chat (synchronous) sessions. Another ASYNC+SYNC student suggested that since only the professor, not students, had access to a microphone, the synchronous sessions "felt like a conference call," because "[text-based] chatting is not the best way to communicate in a group setting."

\section{Social Community and Learning Community}

The purpose of this study was to explore the impact of synchronous interaction on student achievement and engagement, specifically students' perception of community within the online classroom. To measure perceptions of community, we included the 10-item Classroom Community Inventory (Rovai, Wighting, \& Lucking, 2004) with the end-of-course evaluation materials. Five of the items on the scale measure "social community," and five measure "learning community," with 1=Strongly Disagree and 5=Strongly Agree. In the ASYNC+SYNC section, social community was rated slightly higher than in ASYNC; however, a Mann-Whitney U test showed no statistical significance in this difference, as outlined in Table 4.

Overall, therefore, there were no statistically significant differences apparent between the ASYNC and ASYNC+SYNC sections of the course. When they addressed the inclusion of synchronous lectures specifically, ASYNC+SYNC students gave no indicator that the Adobe Connect sessions added to their learning. Survey results and grade data suggest there was no significant gain in terms of academic 
Is It Worth the Effort? The Impact of Incorporating Synchronous Lectures into an Online Course

achievement, social community, or learning community for those participating in ASYNC+SYNC. These findings are discussed more fully in the following section.

Table 4 Perceived Social Community and Learning Community in ASYNC and ASYNC+SYNC Sections

\begin{tabular}{|c|c|c|c|c|c|c|}
\hline & \multicolumn{2}{|c|}{ ASYNC } & \multicolumn{2}{|c|}{$\underline{\text { ASYNC+SYNC }}$} & \multirow{2}{*}{$\begin{array}{l}\text { Mann- } \\
\text { Whitney U }\end{array}$} & \multirow{2}{*}{$\begin{array}{l}\text { Exact } \\
\underline{\text { Sig. }}\end{array}$} \\
\hline & Mean & $S D$ & Mean & $S D$ & & \\
\hline Social Community & 19.4 & 2.95 & 19.6 & 3.63 & 46.5 & .796 \\
\hline Learning Community & 19.9 & 3.28 & 19.9 & 4.12 & 49.0 & .971 \\
\hline
\end{tabular}

\section{Discussion}

This case study explored the potential benefits of adding synchronous lectures to a primarily asynchronous online course. We found no significant differences between the ASYNC and ASYNC+SYNC sections on measures of academic achievement, social and learning community, or course satisfaction. At the very least, this study suggests that incorporating synchronous activities requires careful consideration of the impact of this move on student achievement, student experience, and institutional investment.

\section{Consider the Student's Achievement}

We used three different measures (total discussion forum score, total score on "targeted" assignments, and final course grade) to compare student achievement across the two sections. Grades in ASYNC were slightly higher than in the other section. This suggests that the instructor was not biased toward the ASYNC+SYNC section (i.e., the "treatment" condition); these differences were not found to be statistically significant. On each of these measures, students in ASYNC received higher grades than ASYNC+SYNC, although none of the differences rose to the $\mathrm{p}<.05$ level. This echoes Johnson's (2008) findings, and it is possible to view this result in two ways. On one hand, as there was no demonstrated, statistically significant benefit for the ASYNC+SYNC students, the inclusion of synchronous lectures could be interpreted as an unnecessary investment, one that does not produce significant gains in student learning. At the same time, there was no demonstrated detriment that occurred for the students included in ASYNC+SYNC. For the institution where students and instructor were already comfortable with these types of technologies (Bower, 2011), with the infrastructure to support synchronous activities already in place (Falloon, 2011), these findings might suggest that while adding synchronous activities may not enhance student academic achievement, they may appeal to students and therefore provide a strategic edge in marketing. When considering this move, it is critical to remember that the student may have chosen a program based on the requirements of a particular modality; adding a synchronous component also constrains the student to participating in class activities at a particular time and place in a way that may not be possible or preferable for the student.

\section{Consider the Student's Experience}

This study also explored the impact of synchronous lectures on student experience, in terms of social and learning community within the class. If the incorporation of synchronous lectures had produced significant gains in terms of social community or learning community-even where no significant differences in academic achievement were noted - this increase in the student's experience of "presence" in an online course (Garrison \& Anderson, 2003; Palloff \& Pratt, 2011) might also lead to increased student retention and persistence. The absence of significant differences on these two scales suggests simply adding synchronous lectures is not sufficient to produce increases in either social community or learning community. It is not a magic bullet. It may also be possible that students will 
Is It Worth the Effort? The Impact of Incorporating Synchronous Lectures into an Online Course

develop social community or learning community by utilizing whatever technologies are provided for them, whether that is fully asynchronous or some combination of asynchronous and synchronous settings.

As others have noted (Bower, 2011; Falloon, 2011), the "real-time" nature of synchronous instruction introduces an element of unpredictability that can greatly impact the student's experience within the classroom. As students here noted, when given the opportunity to respond to open-ended prompts, the synchronous sessions tended to get "off track" or be "not focused." Furthermore, several of the course design decisions the design team made (e.g., muting students' microphones to reduce potential technology challenges) were viewed by the students as reducing the potential of the synchronous sessions to enhance their learning experience. In addition, requiring students to attend a synchronous session at a specific time may have resulted in students "attending" class at times they perceived to be less than optimal, thereby influencing their experience of community within the classroom.

\section{Consider the Investment}

In preparing for these classes and this study, the design team invested significant time and resources. The institution already had access to Adobe Connect through a college-wide site license, which enabled us to pursue this study without an investment of financial resources. However, the investment -in terms of human resources-was substantial: rewriting syllabi and updating course shells to reflect the change in format for the ASYNC+SYNC session, contacting students before the class to insure their ability and willingness to participate in the synchronous sessions, providing several Adobe Connect orientation sessions for students, training the instructor in the use of the Adobe Connect environment, and testing the environment before the class began. In the end, the data here suggests no notable differences in either learning or community outcomes between a fully asynchronous course and one that intentionally incorporated synchronous lectures into the course design.

\section{Limitations and Future Research}

Students in this five-week accelerated course, populated with primarily non-traditional learners who had previously taken online courses using only asynchronous modalities, may not be typical of all online learners, thereby limiting the generalizability of these results to similar students in similar settings. In addition, the study presented here is taken from two small class sections, resulting in small sample sizes and limited statistical power. We also recognize the possibility of selection bias that is a result of allowing students to switch out of ASYNC+SYNC if they were unable or unwilling to commit to the synchronous sessions. In spite of significant pre-class preparation and training, as well as self-reported comfort using new technologies as indicated on the end-of-class evaluation, both students and instructor experienced technical difficulties while working with the synchronous (Adobe Connect) technology, which may have impeded the sense of social community or learning community that those students might otherwise have experienced. To limit variability between ASYNC and ASYNC+SYNC, we purposefully used two sections taught by the same instructor; it is possible that what we have reported here may be idiosyncratic to this instructor. It is also possible that the Classroom Community Inventory more accurately measures social community or learning community as it would develop in a full-semesterlength class; five weeks may simply be too short to foster the types of relationships that are perceived as social community or learning community.

Given the accelerated nature of this course and the technical difficulties that participants experienced, researchers may benefit from comparing social and learning community as it is perceived and experienced by students in a longer class or when students use these technologies for the second time. In addition, conducting synchronous sessions with student microphones enabled (rather than muted, as we chose to do for this study) might allow for more spontaneous interaction and natural reactions that could influence. This study focused on presenting academic content using synchronous lectures (i.e., teacherstudent interaction); the impact of synchronous activities on student-student interaction should also be explored. It would also be beneficial to explore the impact of synchronous technologies with multiple instructors, each of whom are teaching two sections of the same course to more accurately pinpoint the impact of the synchronous activities, over and above the influence of the course instructor. 
Is It Worth the Effort? The Impact of Incorporating Synchronous Lectures into an Online Course

\section{Conclusion}

As broadband and other technologies become more readily accessible, program planners, instructional designers, and administrators will likely find themselves considering how these technologies could be incorporated into course and program offerings. "Real-time" classes and "live" instructors may make for effective marketing, but do these features enhance student learning? Educators need to evaluate carefully the impact of technology on the real experiences and learning outcomes of students, moving beyond rhetoric and intuition. The absence of significant differences between ASYNC and ASYNC+SYNC presented here suggests that learning outcomes were not enhanced by the incorporation of synchronous lectures into an online course. The findings here suggest that it is necessary to consider the student's learning, the student's experience, and the investment of time and resources when evaluating whether it is "worth the effort" to incorporate synchronous activities into an online course.

\section{References}

Baker, C. (2010). The impact of instructor immediacy and presence for online student affective learning, cognition, and motivation. The Journal of Educators Online, 7(1), 1-30.

Bower, M. (2011). Synchronous collaboration competencies in web-conferencing environments-their impact on the learning process. Distance Education, 32(1), 63-83. doi: 10.1080/01587919.2011.565502

Exter, M. E., Korkmaz, N., Harlin, N. M., \& Bichelmeyer, B. A. (2009). Sense of community within a fully online program: Perspectives of graduate students. The Quarterly Review of Distance Education, 10(2), 177-194.

Falloon, G. (2011). Making the connection: Moore's theory of transactional distance and its relevance to the use of a virtual classroom in postgraduate online teacher education. Journal of Research on Technology in Education, 43(3), 187-209.

Garrison, D. R., \& Anderson, T. (2003). E-learning in the 21st century. London, England: RoutledgeFalmer.

Hall A., \& Herrington, J. (2010). The development of social presence in online/Arabic learning communities. Australasian Journal of Educational Technology, 26(7), 1012-1027.

Hrastinski, S. (2008). Asynchronous and synchronous e-learning. A study of asynchronous and synchronous e-learning methods discovered that each supports different purposes. Educause Quarterly, 4, 51-55.

Hrastinski, S., Keller, C., \& Carlsson, S. A. (2010). Design exemplars for synchronous e-learning: A design theory approach. Computers \& Education, 55(2010), 652-662. doi: 10.1016/j.compedu.2010.02.025

Johnson, G. (2008). The relative learning benefits of synchronous and asynchronous text-based discussion. British Journal of Educational Technology, 39(1), 166-169. doi: 10.1111/j.14678535.2007.00739.x

Melkun, C. H. (2012). Nontraditional students online: Composition, collaboration, and community. The Journal of Continuing Higher Education, 60, 33-39. doi: 10.1080/07377363.2012. 649128

Oztok, M., Zingaro, D., Brett, C., \& Hewitt, J. (2013). Exploring asynchronous and synchronous tool use in online courses. Computers \& Education, 60, 87-94. doi: 10.1016/j.compedu.2012.08.007

Palloff, R. M., \& Pratt, K. (2011). The excellent online instructor: Strategies for professional development. San Francisco, CA: Jossey-Bass.

Pattillo, R. E. (2007). Decreasing transactional distance in a web-based course. Nurse Educator, 32(3), 109-112.

Rockinson-Szapkiw, A. J., Baker, J. D., Neukrug, E., \& Hanes, J. (2010). The efficacy of computer 
Is It Worth the Effort? The Impact of Incorporating Synchronous Lectures into an Online Course

mediated communication technologies to augment and support effective online helping profession education. Journal of Technology in Human Services, 28, 161-177. doi: 10.1080/15228835.2010.508363

Rovai, A. P. (2001a). Classroom community at a distance: A comparative analysis of two ALN-based university programs. Internet and Higher Education, 4, 105-118.

Rovai, A. P. (2001b). Building classroom community at a distance: A case study. Educational Technology Research and Development, 49(4), 33-48.

Rovai, A. P. (2002). Development of an instrument to measure classroom community. Internet and Higher Education, 5, 197-211.

Rovai, A. P., \& Jordan, H. M. (2004). Blended learning and sense of community: A comparative analysis with traditional and fully online graduate courses. International Review of Research in Open and Distance Learning, 5(2), 1-13.

Rovai, A. P., \& Lucking, R. (2003). Sense of community in a higher education television-based distance education program. Educational Technology Research and Development, 51(2), 5-16.

Rovai, A. P., Wighting, M., \& Lucking, R. (2004). The classroom and school community inventory: Development, refinement, and validation of a self-report measure for educational research. The Internet and Higher Education, 7, 263-280.

Schutt, M., Allen, B. S., \& Laumakis, M. A. (2009). The effects of instructor immediacy behaviors in online learning environments. The Quarterly Review of Distance Education, 10(2), 135-148.

Spencer, D. H., \& Hiltz, S. R. (2003). A field study of use of synchronous chat in online courses. Paper presented at 36th Hawaii International Conference on System Sciences. doi: 0-7695-1874-5/03

Stafford, T. F., \& Lindsey, K. L. (2007). IP teleconferencing in the wired classroom: Gratifications for distance education. Journal of Information Systems Education, 18(2), 227-232.

Teng, D. C-E., Chen, N-S., \& Kinshuk, Leo, T. (2012). Exploring students learning experience in an international online research seminar in the Synchronous Cyber Classroom. Computers \& Education, 58, 918-930. doi: 10.1016/j.compedu.2011.10.018 